While this is happening in many peripheral NHS units, teaching hospitals retain their status of having large numbers of trainees concentrated in one place. This will lead to the small units (even if they are part of a patched up rotation) finding it difficult to recruit career junior psychiatrists.

While the Short Report, as I understand it, is no longer the declared Government policy on medical manpower, I can see a situation where this will be happening by default, through the ever widening distinction in the organisation of teaching and non-teaching centres which will lead to the eventual drying up of applicants for peripheral junior jobs.

Fulbourn Hospital

R. T. ABED

Cambridge

\section{The established benefit of psychotherapy} DeAR SIRS

In a refreshing way McGrath \& Lowson (Journal. January 1987, 150, 65-71) moved beyond the well-known and ongoing arguments ${ }^{1}$ over psychotherapy by prioritising the economic appraisal of psychotherapy services. They concentrated on adult services, but Hill \& Cottrell (Bulletin. January 1987, 11, 19-21) offered a timely reminder of the importance of childhood and adolescent psychiatry which serves one quarter of our population. Neither paper, however, specifically mentioned child sexual abuse and it has great relevance for both.

A recent survey ${ }^{2}$ estimated that there are over 4.5 million adults in Great Britain who were sexually abused as children, and that a potential $1,117,000$ children will be sexually abused before they are 15 years of age. The therapeutic approach to sexual abuse has only recently been clarified in this country ${ }^{3}$ and though this is focused more on the family than the individual it is firmly based on psychotherapeutic principles. There is widespread agreement on the use of groups ${ }^{4}$ which pre-empts McGrath's question on efficiency of supply. The denial regarding sexual abuse has been pointed out ${ }^{5}$, but clearly such denial still persists at some level for many professionals. In recognising child sexual abuse and its treatment implications one cannot ignore one established benefit of psychotherapy.

JiM WATTERS

The Tavistock Clinic

London NW3

REFERENCES

'EysencK, H. J. (1987) Psychotherapy and placebo. British Journal of Psychiatry, 150, 266-267.

2BAKER, A. W. \& Duncan, S. P. (1985) Child sexual abuse: a study of prevalence in Great Britain. Child Abuse \& Neglect, 9, 457-467.

${ }^{3}$ Furniss, T., Bingley-Miller, L. \& Bentovim, A. (1984) Therapeutic approach to sexual abuse. Archives of Disease in Childhood, 59, 865-870.

4Steward, M. S., Farquhar, L. C., Dicharry, D. C., Glick, D. R. \& MARTIN, P. W. (1986) Group therapy: a treatment of choice for young victims of child abuse. International Journal of Group Psychotherapy, 36, 261-277.

${ }^{5}$ Lancet Editorial, (1986) Childhood depression and sexual abuse. Lancet, I, 196.

\section{Medical psychotherapist}

\section{DeAR SiRS}

Anyone can call themselves a psychotherapist (cf the personal column of any edition of the Hampstead and Highgate Express), despite attempts to define and restrict the use of the term by various bodies.

The recently created postgraduate degree course in psychotherapy at St George's Hospital Medical School is restricted to medical practitioners and prompts the suggestion that we consider a novel term, Medical Psychotherapist. I propose that this term be restricted to medically qualified practitioners who have satisfactorily managed at least two cases under approved supervision for at least one year each, the trainers to be approved by the Royal College of Psychiatrists and the training to be scrutinised and accredited by the Royal College of Psychiatrists on payment of a registration fee. Such an appelation would have several advantages:

(i) It would motivate the acquisition of the requisite experience by medical students, qualified physicians and psychiatrists in training to the benefit of patients whose psychopathology is often not recognised or little helped at present and it may well induce continuing interest in psychotherapy.

(ii) It would differentiate those so recognised from those who describe themselves as psychotherapists without any training or professional qualifications, and it would raise the standard of practice which, even in the case of the allegedly well trained, can result in consistently poor results. ${ }^{1}$

(iii) It would enable the College to monitor and flexibly promote alternative therapies, such as behavioural and cognitive psychotherapies, and to maintain a register of approved trainers whose status would be confirmed and enhanced.

(iv) It would increase the significance of the College and provide a source of revenue.

Friern Hospital

MALCOLM P. I. WelleR

London N1I

${ }^{1}$ STRUPP, H. H., HadLey, S. W. \& Gomez-SChWaARTZ, G. (1977) Psychotherapy for Better or Worse: The Problem of Negative Effects. New York: Jason Aronson.

\section{Responding to stigma}

DeAr SirS

One public act signifying a reduction in the stigma surrounding psychiatry in Britain would be for the Royal Household to appoint their own specialist in psychiatry as they have done with some other specialties.

Per Lassons vei 17

SimON R. WILKINSON 